\title{
A exibição fílmica do virtuosismo instrumental no documentário musical Nelson Freire
}

\author{
Ludmila Moreira Macedo de Carvalho*
}

\begin{abstract}
Resumo: O artigo promove uma análise do documentário Nelson Freire (2003), procurando demonstrar as estratégias estilísticas utilizadas pelo filme para representar em sons e imagens o virtuosismo do pianista Nelson Freire. Com isso, pretende-se contribuir para uma discussão acerca das múltiplas relações entre música e cinema no documentário musical, um campo do cinema documental em crescimento no Brasil e no mundo.

Palavras-chave: cinema documentário; documentário musical; documentário brasileiro; virtuosismo; performance musical.
\end{abstract}

Resumen: Este artículo realiza un análisis del documental Nelson Freire (2003), buscando demostrar las estrategias estilísticas utilizadas por la película para representar en sonidos e imágenes el virtuosismo del pianista Nelson Freire. Con ello, se pretende contribuir a una discusión acerca de las múltiples relaciones entre música y cine en el documental musical, un campo del cine documental en crecimiento en Brasil y en el mundo.

Palabras clave: cine documental; documental musical; documental brasileño; virtuosismo; actuación musical.

Abstract: This paper presents an analysis of the documentary Nelson Freire (2003), focusing on the stylistic strategies employed by the film to visually represent the virtuosic performance of the Brazilian pianist Nelson Freire. By doing so, we intend to contribute to the general discussion about the multiple relations between music and cinema in the music documentary, a growing field of the documentary cinema in Brazil and abroad.

Keywords: documentary; music documentary; brazilian documentary; virtuosic performance; musical performance.

Résumé : L'article propose une analyse du documentaire Nelson Freire (2003), en essayant de mettre en évidence les stratégies stylistiques utilisées par le film pour représenter dans les sons et les images la virtuosité du pianiste Nelson Freire. Nous avons également l'intention de contribuer à une discussion sur les multiples relations entre la musique et le cinéma dans le documentaire musical, un domaine du cinéma documentaire croissant au Brésil et dans le monde.

Mots-clés : documentaire de cinéma ; documentaire musical ; documentaire brésilien ; virtuosité ; performance musicale.

* Universidade Federal do Recôncavo da Bahia - UFRB, Centro de Cultura, Linguagens e Tecnologias Aplicadas - CECULT / Universidade Federal da Bahia - UFBA, Programa de Pós-Graduação em Comunicação e Culturas Contemporâneas - Poscom. 40 170-115, Bahia, Brasil. E-mail: ludmila@ufrb.edu.br

Submissão do artigo: 22 de fevereiro de 2018. Notificação de aceitação: 17 de julho de 2018. 


\section{Mapeando o documentário musical no cinema brasileiro contemporâ- neo}

Considerado um dos subgêneros mais populares do cinema documental contemporâneo, o chamado "documentário musical" tem tido um rápido e constante crescimento no Brasil nos últimos anos. Segundo dados da Agência Nacional de Cinema (Ancine), ${ }^{1}$ de 2000 a 2014, estrearam nos cinemas brasileiros 77 documentários musicais, contra apenas 18 títulos lançados entre as décadas de 1970 e 1990. Apenas no ano de 2013, foram lançados dez novos filmes, muitos dos quais estão entre os mais vistos pelo público nos cinemas (a exemplo de $A$ luz do Tom, documentário de Nelson Pereira dos Santos sobre Tom Jobim, e A batalha do passinho, registro de Emílio Domingos sobre o fenômeno da dança do passinho nos bailes funk cariocas).

Esse tipo de filme encontrou no país terreno fértil para se desenvolver, não apenas pela inegável qualidade e variedade de músicos, compositores e bandas a serem retratados, mas também, entre outras razões, pela própria ascensão do documentário em suas múltiplas possibilidades no cenário do cinema brasileiro contemporâneo. Fatores que contribuem para esse crescimento vão desde o desenvolvimento de tecnologias mais acessíveis para a produção e distribuição de filmes, até a emergência de festivais especializados ${ }^{2}$ e outras plataformas de exibição que têm contribuído para a formação de uma audiência cada vez maior e mais diversa.

Certamente, tamanho interesse na representação do fenômeno musical em todos os seus aspectos - também não passou despercebido pelo campo teórico. Nos últimos anos, temos visto o aparecimento de diversos estudos realizados por pesquisadores brasileiros (Lapera, 2009; Carvalho, 2012; Lima, 2015) sobre o documentário musical, apontando o gênero como "o lado mais bem-sucedido do gênero documentário que, nos últimos anos, e de maneira sem precedentes, tem demonstrado crescimento notável no país". (Ramos, 2012).

Um dos maiores debates acerca dos documentários musicais parte da própria definição do termo: o que constitui, afinal, um documentário musical? Trata-se de um documentário que utilize a música de maneira proeminente em seu argumento, ou qualquer filme documental que tenha como tema músicos, grupos, movimentos e manifestações musicais? Com efeito, a segunda definição parece prevalecer sobre a primeira quando se analisa o corpus de

1. Observatório Brasileiro do Cinema e do Audiovisual. Listagem de filmes Brasileiros lançados de 1995 a 2014. Disponível em: http://oca.ancine.gov.br/filmes_bilheterias.htm

2. A exemplo do In-Edit (www.in-edit-brasil.com), festival específico de documentários musicais que acontece anualmente nas cidades de São Paulo e Salvador. 
documentários que se autodefinem como musicais lançados nos últimos anos no Brasil. No entanto, torna-se importante salientar que mesmo tal definição se aplica, na prática, a um grupo estilisticamente bastante heterogêneo de filmes, o que revela a um só tempo um material rico para análise e de difícil categorização.

A partir de uma breve cartografia dos títulos lançados no mercado cinematográfico nacional nos últimos dez anos, ${ }^{3}$ foi possível identificar ao menos três grupos principais de documentários musicais, baseados principalmente na temática e no foco dado aos objetos musicais retratados. O primeiro e maior grupo possui uma tendência marcadamente biográfica, ou seja, ocupa-se em criar um retrato da vida e obra de um(a) determinado(a) artista, seja cantor(a), compositor(a), instrumentista, maestro(ina), vivo(a) ou morto(a), geralmente bastante admirado(a) pelo público ou reconhecido(a) pela crítica especializada, salvo raras exceções. Esse tipo de documentário normalmente faz uso de material de arquivo ou de gravações de shows, entrevistas e ensaios para recriar historicamente a trajetória profissional e pessoal do(a) retratado(a), focando, em muitos casos, inclusive nos momentos mais íntimos, fora dos palcos. ${ }^{4}$

Há também aqueles filmes que procuram recuperar historicamente movimentos ou fenômenos musicais importantes (como o crescimento do rock em Brasília a partir da década de 1980, a guitarra baiana nos carnavais de Salvador, as cantoras da época de ouro do rádio ou a Tropicália). Esses filmes geralmente oferecem uma perspectiva mais ampla do que os documentários biográficos, muitas vezes aplicando recursos como o acesso a arquivos históricos, entrevistas com especialistas e encenações para contextualizar as condições sociais, culturais, políticas e históricas que envolvem o aparecimento de determinados fenômenos musicais. ${ }^{5}$

3. Esse exercício de cartografia, assim como a análise que aqui se apresenta, faz parte do projeto de pesquisa "Cinema Musical na América Latina: Ficção e Documentários"desenvolvido pelo núcleo de análise fílmica do Programa de Pós Graduação em Comunicação e Culturas Contemporâneas da UFBA com apoio da FAPESB e do CNPq http://lafposcom.com.br/cinema-musical-na-america-latina/.

4. É o caso de filmes como Paulinho da Viola - Meu tempo é hoje (Izabel Jaguaribe, 2003), Maria Bethânia, música é perfume (Georges Gachot, 2005), Vinícius de Moraes (Miguel Faria Jr., 2005), Fabricando Tom Zé (Décio Matos Jr., 2006), Cartola: música para os olhos (Lírio Ferreira e Hilton Lacerda, 2007), Jards Macalé - Um morcego na porta principal (Marco Abujamra, 2007), Simonal - ninguém sabe o duro que dei (Cláudio Manoel, Micael Langer e Calvito Leal, 2008), Elza (Izabel Jaguaribe e Ernesto Baldan, 2010), Loki - Arnaldo Baptista (Paulo Henrique Fontenelle, 2008), Waldick, sempre no meu coração (Patrícia Pillar, 2008), Herbert de perto (Roberto Berliner e Pedro Bronz, 2009), Um homem de moral (Ricardo Dias, 2009), A música audaz de Toninho Horta (Fernando Libânio, 2011), Jards (Erick Rocha, 2012), Raul Seixas - o início, o fim e o meio (Walter Carvalho, 2012), Cauby - Começaria tudo outra vez (Nelson Hoineff, 2013), Dominguinhos (Mariana Aydar, 2014), entre muitos outros.

5. Como exemplos, podemos citar filmes como Ritmo alucinante - A explosão do rock no Brasil (Marcelo Pietsch França, 1976), Bahia de Todos os Sambas (Leon Hirszman, Paulo César Sarraceni, 1996), Viva São João (Andrucha Waddington, 2002), Brasileirinho - Grandes encontros do choro (Mika Kaurismaki, 2005), Cantoras do rádio (Gil Baroni, Marcos Avellar, 
Num terceiro grupo, encontramos filmes que, em geral, partem da caracterização de um cenário ou gênero musical - como o rap e o funk nas favelas cariocas, ou a cena LGBT nos clubes e boates undergound - para investigar as relações sociais, ideológicas, políticas e culturais entre a música e as pessoas que a produzem e/ou consomem. ${ }^{6}$ Nesse tipo de filme, pode-se argumentar que a música (ou o músico) em si não é o tema do documentário, mas um elemento comum que atravessa as vidas dos agentes sociais reais ali retratados, estes sim os verdadeiros sujeitos do documentário. Nesse sentido, o documentário musical deixa de ser uma plataforma para a representação da música e de seus produtores para se tornar uma via de acesso à investigação de questões que se relacionam às diversas realidades de pessoas comuns. Justamente por isso, muitos desses filmes focam não apenas em músicos profissionais, mas também amadores, e não apenas nos produtores de música como também nos seus consumidores.

Neste artigo, estamos interessados em investigar algo que perpassa os três tipos de documentários musicais: a relação entre o suporte cinematográfico e a performance musical do artista retratado no filme. Seja num retrato biográfico ou no registro de algum fenômeno ou gênero musical, todos os filmes dessa natureza possuem - em maior ou menor medida - cenas de apresentações artísticas, sejam elas gravadas especificamente para o filme ou recuperadas de arquivos históricos. Diferentemente da chamada "música de filme" -, que, mesmo quando é considerada intradiegética, ou seja, quando sua fonte emissora é visível em cena, possui funções dramáticas programadas e inseridas ali por uma instância narrativa maior (Gorbman, 1987) -, as imagens de apresentações e shows nos documentários musicais estão diretamente ligadas ao corpo do artista que produz a música, ou seja, à sua presença física no momento em que é produzida. Qual o papel do cinema nesta relação entre performance musical e imagem? O que significa documentar em imagens uma performance artística que, em sua própria natureza, evoca um ato único, irrepetível temporal e espacialmente? O que se perde e o que se ganha na passagem de uma linguagem para outra?

2008), Filhos de João, admirável mundo novo baiano (Henrique Dantas, 2009), Uma noite em 67 (Renato Terra, Ricardo Calil, 2010), Rock Brasília, Era de ouro (Vladimir Carvalho, 2011), Tropicália (Marcelo Machado, 2012), Damas do samba (Susanna Lira, 2013), Geração Baré-Cola - Usuários de Rock (Patrick Grosner, 2014) e Guitarra baiana - A voz do carnaval (Daniel Talento, 2014).

6. Exemplos incluem os filmes Aqui favela, o rap representa (Júnia Torres, Rodrigo Siqueira, 2003), Sou feia mas tô na moda (Denise Garcia, 2005), L.A.P.A. (Emílio Domingos e Cavi Borges, 2008), Favela on blast (Leandro HBL e Wesley Pentz, 2008), Dzi Croquettes (Tatiana Issa, Raphael Alvarez, 2009), A batalha do passinho - O filme (Emílio Domingues, 2012) e São Paulo em hi-fi (Lufe Steffen, 2013). 


\section{Documentário e performance musical}

O autor Thomas F. Cohen, em seu livro Playing to the câmera (2012), aponta que os documentários musicais estiveram historicamente sempre à margem do cinema, apesar de terem sido bastante populares, desde a criação do rockumentary nos anos 1960 e os registros da ascensão de inúmeros ídolos do pop e do rock até os dias de hoje. Na maioria das vezes, costumam ser considerados como um mero veículo de promoção de um artista ou banda sem maiores virtudes cinemáticas, sobretudo por não querer convencer ou educar o espectador a respeito de um tema relevante socialmente. "O documentário musical tende a operar de acordo com uma lei tácita segundo a qual o realizador olha para o músico com os olhos de um fã, o que resulta num filme visto como essencialmente promocional e indigno de atenção séria". ${ }^{7}$ (Chanan, 2013: 337, tradução nossa).

Mesmo no campo musical, tais filmes costumam sofrer preconceito: os filmes dedicados exclusivamente à performance, como os registros de concertos, de shows e de festivais musicais, por exemplo, são taxados de entediantes e pouco criativos, material produzido ou encomendado pelas gravadoras e destinado apenas aos fãs mais ardorosos dos artistas em questão. Além disso,

Uma razão importante pela qual os filmes de shows entediam muitos críticos é porque eles não apresentam uma narrativa na qual as mudanças de situações podem ser traçadas às motivações dos personagens; além disso, as pessoas retratadas nestes filmes não demonstram um grau de complexidade psicológica ou emocional suficiente, ao menos não enquanto estão tocando no palco. ${ }^{8}$ (Cohen, 2012: 10, tradução nossa).

Em outras palavras, os documentários musicais, sobretudo aqueles que privilegiam os momentos de performance musical, não se comportam nem como filmes narrativos clássicos, com personagens psicologicamente bem delineados e papéis narrativos claramente definidos, nem como documentários clássicos, apresentando argumentações convincentes acerca de temas ou questões socialmente relevantes. Por conta disso, tendem a ser ignorados tanto pelos estudos de cinema quanto pelos estudos de música.

Jean-Louis Comolli, no ensaio "Algumas pistas paradoxais para passar entre música e cinema" (2004), aponta que muitos filmes dessa natureza se limitam a "filmar músicos tocando" e que isso não bastaria para tornar a música

7. "Music documentary tend to operate according to an unwritten law in which the filmmaker looks at the musician with the eyes of the fan, which results in the film being seen as essentially promotional material and therefore unworthy of serious attention".

8. "One important reason that the concert film bores many critics and filmgoers is because it does not present a narrative in which changing situations can be traced to characters' motives; moreover, people in these films do not evince a sufficient degree of psychological complexity or emotional depht, at least not while performing on stage". 
visível. Segundo o autor, o registro da produção musical "como um mero trabalho do corpo", o mero registro do artista enquanto toca, reduz o cinema a uma espécie de grau zero de arquivo ontológico da performance daquele músico específico que pouco acrescentaria às possibilidades fílmicas (ou musicais, por outro lado).

Raciocínio semelhante poderia ser aplicado aos registros documentais de outras artes do corpo, como a dança, o teatro e a performance. Pensando no campo específico das artes performáticas, o autor Philip Auslander (2006) aponta que existe de fato um caráter ontológico na base da documentação visual, seja ela fotográfica ou cinematográfica, de performances artísticas. O registro em imagens de um acontecimento único, produzido para a fruição de uma audiência in loco, teria, antes de mais nada, esse caráter suplementar de evidência de que o ato de fato ocorreu. "A ideia do documentário como meio de acessar a realidade da performance deriva da ideologia geral da fotografia" ${ }^{9}$ (Auslander, 2006: 1, tradução nossa), ou seja, da ideia de que há uma correspondência indexical entre a imagem capturada e o evento ocorrido originalmente.

Auslander aponta, entretanto, que o registro fotográfico ou imagético de uma performance não se limita à simples documentação de um acontecimento original que teria ocorrido de qualquer maneira. Há uma relação de mútua suplementação, na medida em que a performance precisa do registro para comprovar sua existência tanto quanto o documentário precisa da performance como material original, âncora de sua indexicalidade. Nesse sentido, "a performance é sempre em algum nível material cru para a documentação, produto final através do qual ela [a performance] será circulada e com o qual inevitavelmente será identificada". ${ }^{10}$ (Auslander, 2006: 3, tradução nossa).

Voltando a falar do registro de performances musicais, Cohen afirma que mesmo o mais banal documentário de um show seria capaz de oferecer, entre outras coisas, uma rica interação entre as artes do cinema e da música. Ao colocar imagens de músicos reais em cena, o documentário musical automaticamente cria uma relação entre o som e o corpo que o produz naquele momento da captação da imagem. Segundo o autor, essa relação direta com a fonte produtora (uma pessoa de carne e osso, com todas as suas características ali exibidas) pode nos dar uma perspectiva valiosa sobre a própria dinâmica física da performance musical, muitas vezes mudando a percepção que o espectador tem daquela música ou artista. (Cohen, 2012: 11).

9. "The idea of the documentary as a means of accessing the reality of the performance derives from the general ideology of photography".

10. "The performance is always at one level raw material for documentation, the final product through which it will be circulated and with which it will inevitably become identified". 
Tendo isso em vista, apresentamos uma análise de Nelson Freire (2003), de João Moreira Salles, documentário sobre a vida e a obra do célebre pianista brasileiro Nelson Freire. Ao escolher um documentário sobre um instrumentista reconhecidamente virtuoso em sua técnica, procuramos justamente verificar como as habilidades artísticas e expressivas do músico em questão são representadas cinematograficamente.

\section{Representando o virtuosismo em Nelson Freire (2003)}

Embora não tenha uma narrativa cronologicamente linear nem procure utilizar os recursos mais tradicionais das biografias - como narração em off, depoimentos de amigos, familiares ou especialistas -, pode-se caracterizar $\mathrm{Nel}$ son Freire como um documentário musical de cunho biográfico, uma vez que seu foco está tanto na obra quanto na personalidade do pianista Nelson Freire fora dos palcos. Dos 94 minutos de filme, 46 são dedicados à performance (seja em ensaios ou shows), ou seja, um pouco menos que a metade do filme. O restante é preenchido com cenas do músico em momentos de bastidores, seja antes dos concertos, praticando seus rituais de concentração, seja depois, recebendo os aplausos e agradecimentos da plateia, ou em casa.

Segundo Thomas Cohen, documentários musicais de cunho biográfico têm sido populares desde a década de 1960, com o lançamento de filmes que registraram a ascensão de astros do rock como Bob Dylan, os Rolling Stones e os Beatles. Filmes como Don't look back (Don Pennebaker, 1967), e Gimme shelter (David e Albert Maysles, 1970), rodados por cineastas reconhecidos do cinema direto americano, forneciam um olhar não só sobre os artistas no palco, mas sobretudo fora deles, com inúmeras cenas de entrevistas, momentos nos bastidores, ensaios, viagens e preciosos momentos de ócio. Esta tentativa observacional de privilegiar momentos autênticos, muitas vezes não roteirizados e não ensaiados, relaciona-se à tentativa, reconhecidamente ingênua, de revelar a pessoa "real" por trás da persona pública do músico. "Paradoxalmente", diz Cohen (2012: 54, tradução nossa), "o cinema direto representa pessoas que tornaram-se famosas pelos seus talentos performáticos como mais interessantes quando estão fazendo outra coisa além da performance". ${ }^{11}$

Em Nelson Freire, há um claro privilégio de momentos aparentemente banais e também intimistas da vida do artista, que é mostrado em sua casa ouvindo música, assistindo a filmes e comentando sobre eles; procurando uma partitura perdida, limpando calmamente as teclas do piano, fazendo carinho na cadela de estimação etc. As informações a respeito de sua vida, bem como os

11. "Paradoxically, direct cinema represents people whose performing talent accounts for their celebrity as most interesting when doing something other than performing in public". 
traços de sua personalidade, são absorvidas através desses pequenos fragmentos dispersos ao longo dos 32 blocos de filme, separados por intertítulos.

Um desses traços de personalidade, e que depois será corroborado nas sequências de performance, é justamente a introspecção e a solidão de Freire: além da companhia da cadela de estimação e também da sua amiga de longa data e pianista Martha Argerich, não se vê o músico com família ou amigos. Ao contrário, ele está sempre falando de ausências - a saudade da primeira professora de piano, a distância entre ele e os irmãos - ou então participando de encontros superficiais com jornalistas ou fãs, que, passados os primeiros momentos de euforia após um concerto, por exemplo, não têm muito o que dizer. Essa sensação de isolamento espelha-se na profissão do pianista e, em diversos momentos, é corroborada nas sequências de performance: ele mesmo explica que trata-se de uma profissão solitária, na qual, mesmo nos momentos em que divide o palco com outro pianista ou com uma orquestra, ele está sempre isolado ao piano.

O que dizer, então, dos demais 46 minutos de filme dedicados à performance? Quais são as estratégias estilísticas utilizadas para render visível a maestria do pianista ao seu instrumento? Diferentemente de filmes sobre músicos já falecidos, por exemplo, em que o diretor possui apenas material de arquivo e precisa trabalhar essencialmente com a edição das imagens, ${ }^{12} \mathrm{em}$ Nelson Freire, João Moreira Salles teve a oportunidade de gravar pessoalmente as apresentações musicais do pianista. O realizador acompanhou Freire em concertos em diversos palcos do mundo durante um período de dois anos, o que lhe rendeu, além de um vasto material de trabalho, uma certa liberdade para controlar a movimentação e o posicionamento das câmeras.

Isso se vê principalmente nas cenas de ensaios. Como o palco não precisa ser preservado para uma performance pública, nas cenas de ensaios, a câmera na mão do realizador literalmente invade o palco, segue o pianista mais de perto, acompanha sua movimentação até o piano, passando por outros músicos da orquestra e oferecendo um ponto de vista privilegiado ao espectador.

Já nas cenas de ensaios e apresentações públicas, o diretor está um pouco mais restrito aos próprios limites espaciais do palco. Nesses casos, ele recorre a uma pequena variação de planos gerais, médios e primeiros planos feitos a partir do ponto de vista da plateia: há, quase sempre, a apresentação de um

12. Um exemplo interessante disso é o filme Paulo Moura - Alma brasileira (2013), de Eduardo Escorel. Quando estava pronto para filmar o documentário, o cineasta ficou sabendo da internação e subsequente morte do músico multi-instrumentista. O filme que havia sido planejado com a presença do músico não podia mais ser feito. "Restava desistir do projeto, ou então procurar uma alternativa entre os vestígios", relata o cineasta no próprio filme, que terminou tornando-se uma recuperação de centenas de horas de gravações de performances do músico. 
plano geral bastante aberto, no qual é possível localizar o pianista no palco, seja ele centralizado em relação ao ângulo de visão da plateia ou em plongée, ou seja, de um ponto de vista superior ao palco (figura 1). Além de contextualizar a ação espacialmente, como é normalmente a função dos planos gerais de estabelecimento, essas imagens mais abertas conseguem enfatizar, ao mesmo tempo, o isolamento de Freire no centro do palco com seu instrumento, iluminado pela luz dramática do espetáculo, e a grandeza e imponência dos palcos em que toca. No entanto, a esta distância, não é possível ver nenhum detalhe da expressão do artista.
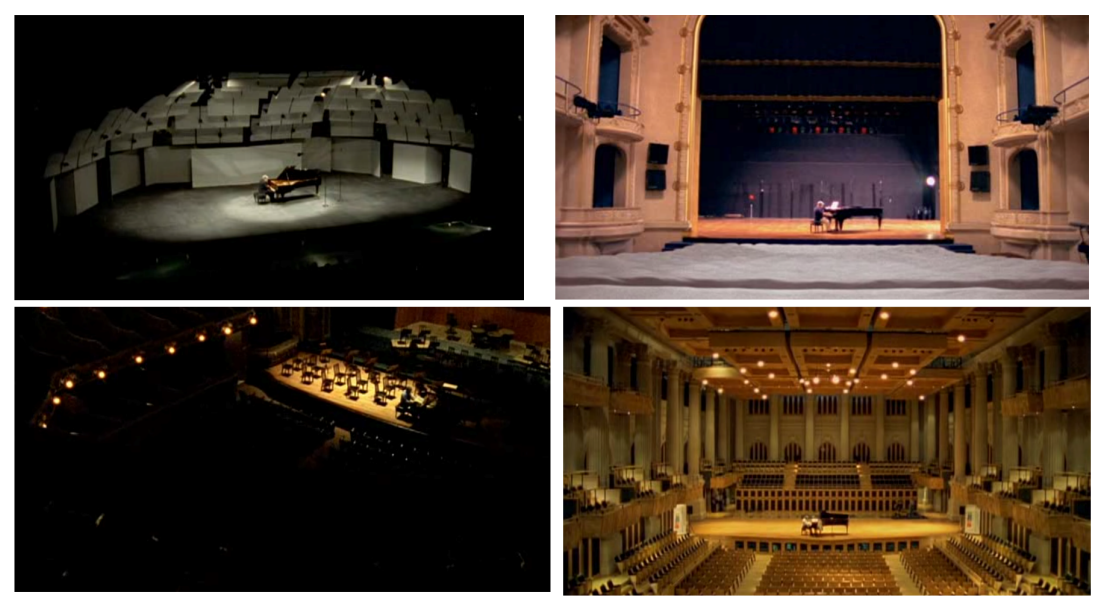

Figura 1. Planos gerais do palco

Esses planos gerais podem ou não deixar ver a presença da plateia, mas há alguns poucos contraplanos que são feitos do ponto de vista do palco em direção à plateia - estes também representam um ponto de vista privilegiado, pois tornam possível ao espectador acompanhar, ao mesmo tempo, a performance do pianista e a reação da plateia (figura 2). 

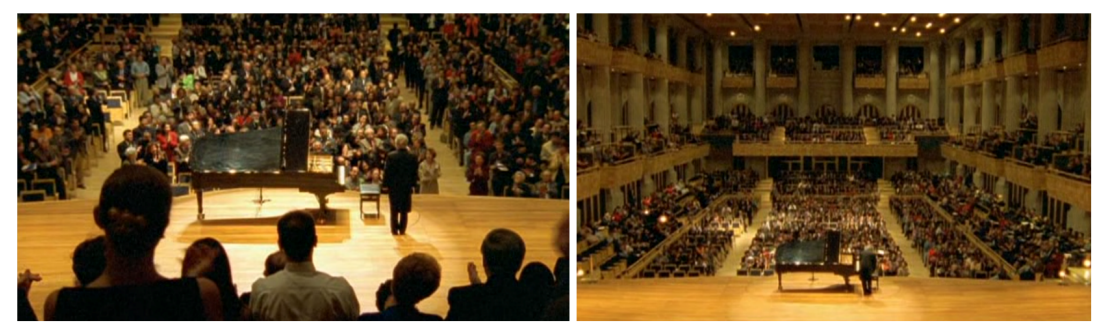

Figura 2. Ponto de vista do palco

Há também a utilização recorrente de um plano médio, que enquadra a totalidade do piano no centro da imagem, e alguns planos americanos que enquadram o pianista da cintura para cima. Nesses casos, já não é possível ver o palco (e em alguns casos nem mesmo o piano) em sua totalidade, mas torna-se possível acompanhar a expressão do pianista com maior facilidade. Os planos médios e planos americanos, normalmente utilizados no cinema de ficção em situações de diálogo, neste caso permitem ter uma visão suficientemente aproximada do pianista em sua performance, mas ainda suficientemente distante para que se tenha uma contextualização espacial do artista no palco.
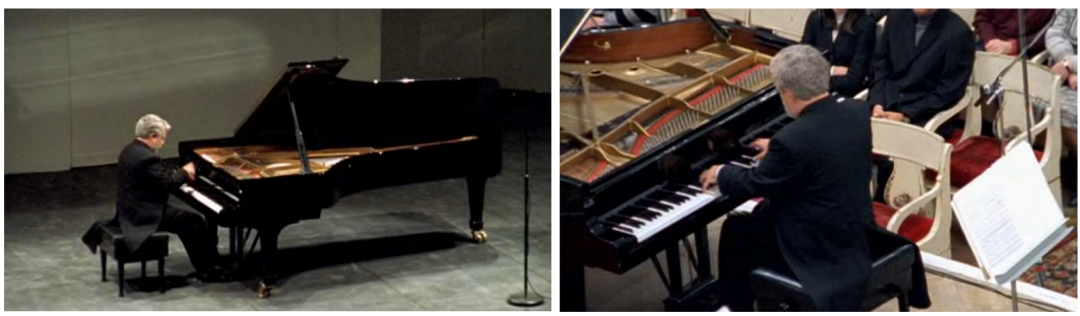

Figura 3. Plano médio e plano americano do pianista

São, no entanto, os primeiros planos que se destacam, seja do rosto de Nelson Freire tocando ou de suas mãos. Os primeiros planos do rosto quase sempre enquadram o músico de perfil (um ou outro são feitos de frente) e revelam um semblante praticamente impenetrável, introspectivo, olhando sempre para o piano, extremamente concentrado no seu fazer artístico (figura 4). 

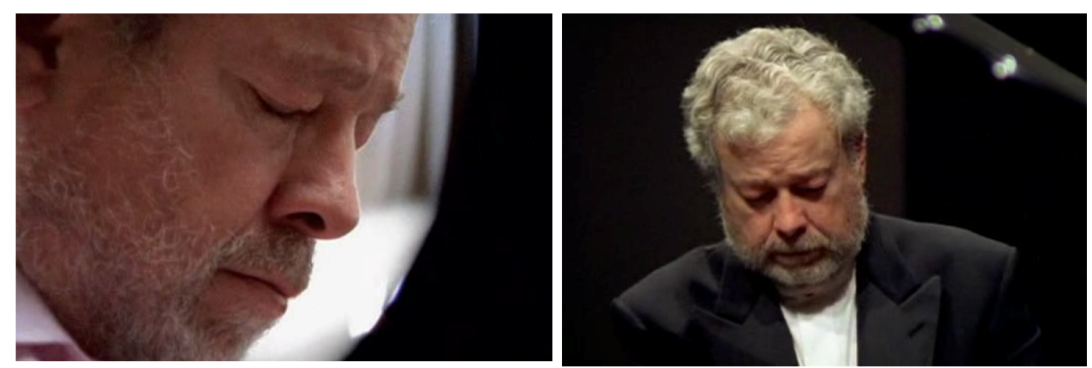

Figura 4. Primeiros planos do rosto

Cohen (2012: 10) afirma que os músicos normalmente não transmitem um grau suficiente de complexidade psicológica ou densidade emocional enquanto estão tocando. Isto porque o corpo que produz música está ali independentemente dos objetivos do cineasta; seus gestos e movimentos corporais não obedecem ao desejo do realizador na verdade são alheios a ele e são compreensíveis em toda sua dimensão apenas para os conhecedores de música.

Nas sequências de concertos públicos, é interessante notar que a câmera percebe um sujeito que já estaria se apresentando independentemente dela, portanto, um sujeito que já se encontra performando para um público. Isso não significa dizer que o músico ignora a presença da câmera (assim como ele não ignora a presença do público), mas que seus movimentos e ações independem dela, não são feitos para ela. A câmera porta-se, dessa maneira, como um observador.

Se há uma audiência para a qual a performance é dirigida, ou se a câmera faz parte de um encontro privado onde pessoas tocam umas para as outras, alguém fazendo música já é alguém performando um papel o qual a câmera, em circunstâncias favoráveis, pode observar sem afetar, porque fazer música é uma forma de comportamento que por si só já envolve uma pessoa inteira num ato de comunicação expressiva. ${ }^{13}$ (Chanan, 2013: 341, tradução nossa).

Se, no entanto, os primeiros planos do rosto do músico revelam pouca expressão além da ideia de concentração, os primeiros planos das mãos do pianista, também quase sempre enquadradas lateralmente ou diagonalmente, cumprem a função de revelar toda a destreza, a habilidade manual de Nelson Freire ao piano (figura 5). A velocidade com que os dedos do pianista se movem sobre as teclas do piano é difícil de ser acompanhada pelos olhos

13. "Wether there's an audience to whom the performance is directed, or the camera is part of a private gathering where people are playing for each other, someone making music is already performing a role which the camera, in favourable circumstances, can observe without affecting, because making music is a form of behaviour that already involves the whole person in an act of expressive communication". 
do observador (as tentativas de congelar a imagem para obter esses frames quase sempre resultaram em imagens borradas, tamanha é a movimentação das mãos). Tais planos revelam toda a dimensão da visão privilegiada da câmera da cinema, uma vez que tal aproximação jamais seria possível ao espectador comum presente aos concertos.
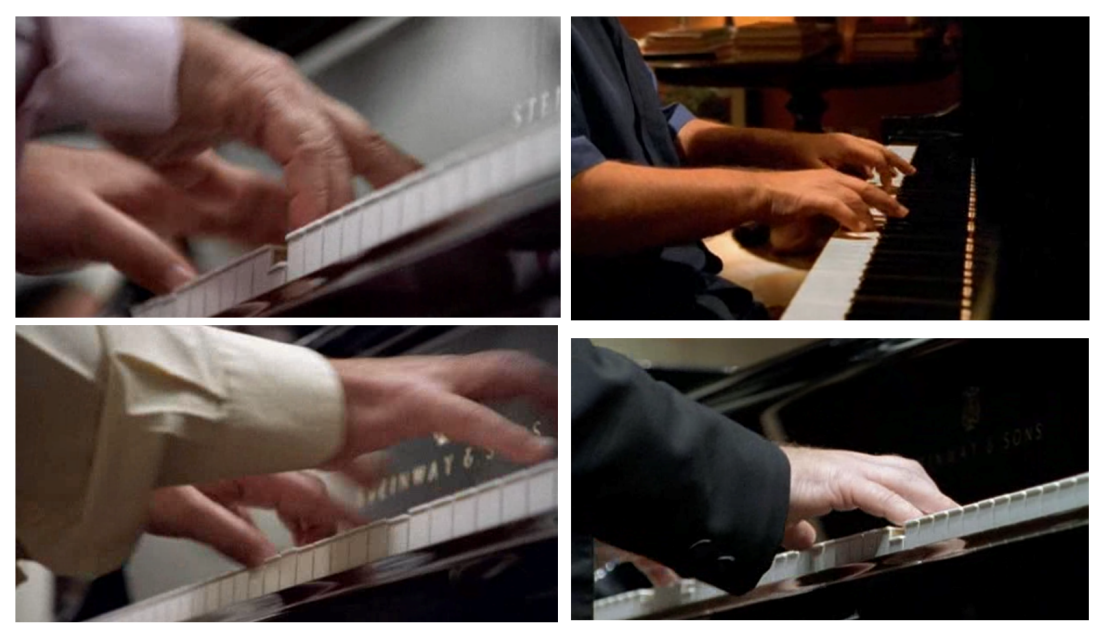

Figura 5. Planos-detalhe das mãos

Um outro recurso expressivo utilizado nesse filme são os primeiros planos do rosto, não do músico tocando, mas da plateia ouvindo-o tocar. João Moreira Salles utiliza esse recurso com admirável parcimônia, num único espetáculo em que, depois de passar pelos planos usuais de apresentação do pianista, a câmera "passeia" pelos rostos de membros da plateia enquanto admiram, com expressões faciais que variam da placidez ao deslumbramento (há um senhor, inclusive, de olhos fechados, em pura expressão de êxtase), a música de Freire (figura 6). É evidente que tal recurso, diferentemente dos demais, não possui a função de representar ao espectador a performance do músico, mas sim o efeito dessa performance na audiência, o que é também uma parte importante do documentário musical. Se a expressão facial e corporal do pianista revela poucas emoções, uma vez que ele está concentrado no seu fazer artístico, uma das maneiras de representar a emoção provocada por este fazer está em recorrer a imagens da audiência. 

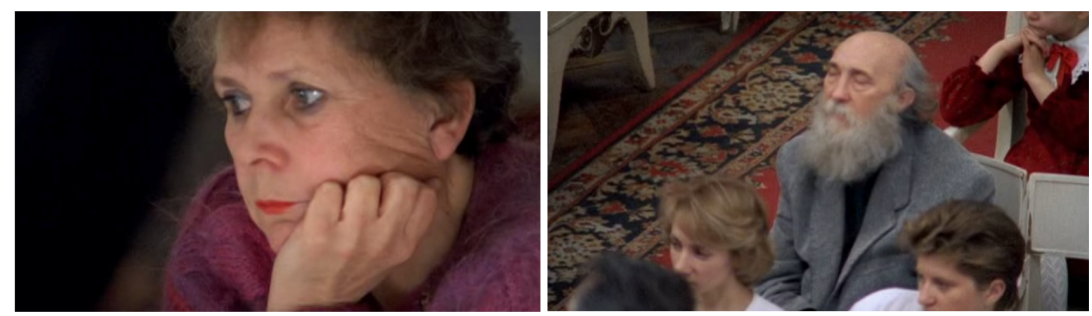

Figura 6. Reações da plateia

Por fim, outra característica importante de se perceber a respeito das sequências de performance está no seu encadeamento: ao invés de seguir uma montagem que privilegie a continuidade temporal, o filme frequentemente agrupa diversos fragmentos imagéticos unidos pela continuidade musical. Por exemplo, há diversas sequências que revelam o pianista tocando a mesma obra, porém em lugares diferentes; ou então momentos em que o mesmo trecho de uma obra é repetido num ensaio e depois na sua apresentação ao público. Esse tipo de montagem privilegia a continuidade da música, tornando possível fruir uma peça em sua integridade (em muitos documentários musicais, isso não ocorre, visto que as músicas são frequentemente interrompidas pela montagem).

Além disso, pode-se dizer que o agrupamento "temático" das sequências, ao invés de temporal, revela a clara intenção de enfatizar o caráter repetitivo do labor artístico do pianista (em lugares diferentes, mas sempre repetindo os mesmos gestos, os mesmos movimentos), bem como o caráter ritualístico de sua vida (desde o ritual que envolve a afinação do piano, a interação com a orquestra, os agradecimentos do público, a lida com a imprensa etc.).

\section{Considerações finais}

Como vimos anteriormente, há uma variedade enorme de estilos, temas e abordagens possíveis dentro do que chamamos de documentário musical, que pode ir dos filmes mais promocionais e biográficos aos mais históricos e sociais. O que nenhum desses filmes pode prescindir, entretanto, é de momentos de performance musical, ou seja, de cenas que mostram os músicos efetivamente tocando, seja através de acesso a material de arquivo ou de cenas filmadas especificamente para o documentário em questão. De maneira geral, podemos dizer que quanto maior o foco na música, mais momentos de performance em detrimento de cenas de bastidores e momentos biográficos, por exemplo. 
O problema é que, frequentemente, são justamente esses momentos de performance, que "simplesmente filmam o músico tocando", que fazem com que o documentário musical, especialmente o mais focado na música, seja taxado de entediante, pouco inventivo ou alienante para grande parte do público. De fato, para aqueles que não são admiradores do músico em questão ou que não entendem tecnicamente de música - especialmente no caso de música instrumental, em que não há recurso à expressividade mais universal da voz ou das palavras de uma canção -, a experiência de assistir a um documentário musical pode tornar-se seletiva. "Alguns espectadores apreciam o filme a despeito da performance musical ao invés de por causa dela". ${ }^{14}$ (Cohen, 2012: 18, tradução nossa).

Cohen (2012: 18, tradução nossa) afirma também que "parece que o valor de um músico como sujeito do documentário depende se ele é mostrado mais tocando ou mais falando". ${ }^{15}$ Essa proporção relaciona-se diretamente à capacidade de identificação do espectador com o sujeito em questão. No segundo caso, há maior possibilidade de investimento emocional e narrativo por parte do espectador - ou seja, há a possibilidade de transformar aquele músico particular em protagonista de uma história, o que naturalmente atrai um público maior e mais variado. As pessoas são atraídas pelos aspectos universais da biografia de uma pessoa - especialmente se sua história reflete uma trajetória de sucesso em frente a obstáculos -, independentemente de conhecerem ou admirarem sua música.

Através da análise de Nelson Freire, percebeu-se uma tentativa de equilíbrio entre os momentos biográficos e os musicais, inclusive na quantidade de tempo dedicado aos dois, mas sobretudo na maneira de representá-los. Ao não seguir uma cronologia linear ou extremamente didática, o filme não se apresenta como uma biografia clássica, nem tampouco coloca-se como veículo de louvação das qualidades humanas do músico. Ao final do filme, temos a impressão de saber um pouco mais sobre a personalidade fechada e tímida de Nelson Freire, mas não tudo. João Moreira Salles utiliza alguns recursos fílmicos, como a escala de planos fechados e a repetitividade enfatizada pela montagem, para retratar algumas características biográficas universais associadas ao pianista, como a concentração, a solidão, a dedicação intensa ao trabalho e, sobretudo, a habilidade que fez dele um dos principais pianistas do país. É importante notar que o realizador recorre a imagens que vão além

14. "Some spectators enjoy the film in spite of rather than because of the musical performances".

15. "It might appear that a musician's value as subject of documentary depends on whether she is shown primarily playing or talking". 
da performance para transmitir uma gama mais variada de emoções e, assim, tentar diminuir o distanciamento entre músico e audiência.

Sobre as sequências de performance propriamente ditas, verificamos que a grande dificuldade do realizador esteve justamente em revelar as habilidades virtuosísticas do músico de uma maneira que não se tornasse alienante ou entediante para o público não especializado em piano ou música erudita. No caso de Nelson Freire, pode-se dizer que o instrumento que ele toca por si só já dificulta na representação da expressividade corporal: diferentemente de outros instrumentos mais leves e que possibilitam ou mesmo incentivam a movimentação corporal, como a guitarra ou o violino, o piano é volumoso e limita os movimentos do instrumentista, que é obrigado a ficar sentado e olhando para baixo, sem fazer muito contato visual com a plateia.

Para solucionar esse problema, o realizador optou pela repetição quase padronizada de uma escala de planos, indo do mais geral, que localiza o espectador no ambiente do teatro onde se dá a performance, até o plano mais fechado do rosto ou das mãos do pianista. Há uma espécie de alternância entre os planos fechados das mãos, que revelam mais de sua técnica, e do rosto, que revelam um pouco mais sobre suas emoções - embora estas tenham permanecido, de certa forma, impenetráveis ao longo do filme. Isso se relaciona, como vimos, ao fato do próprio Nelson Freire ser um pianista extremamente contido, cuja expressividade parece ser sempre mais interna do que externa. ${ }^{16}$ Portanto, mais do que tentar ultrapassá-la, quebrar essa impenetrabilidade, o objetivo do documentário foi o de retratá-la, torná-la visível.

\section{Referências bibliográficas}

Auslander, P. (2006). The performativity of performance documentation. Journal of Performance and Art, 28(03), 1-10.

Carvalho, M. (2012). O rock desligado de Lóki. DOC Online, (12), 75-99.

Chanan, M. (2013). Music, documentary, music documentary. In B. Winston (ed), The documentary film book. NY: Palgrave.

Cohen, T.F. (2012). Playing to the camera: musicians and musical performance in documentary cinema. NY: Wallflower Press.

Comolli, J-L (2004). Algumas pistas paradoxais para passar entre música e cinema. Ver e Poder - a inocência perdida: cinema, televisão, ficção, documentário. Belo Horizonte: UFMG.

16. Há, no filme, uma sequência em que o pianista estuda, um tanto invejoso, o vídeo de uma performance de Errol Garner, este sim um músico bastante expressivo ao tocar o piano ele olha para cima, sorri, mexe a cabeça, os olhos, a boca -, provocando um contraste revelador com a figura do próprio Nelson. 
Gorbman, C. (1987). Unheard melodies: narrative film music. London: BFI.

Lapera, P. V. A. (2009). Funk e rap no documentário brasileiro contemporâneo. Cambiassu, 5(01), 226-246.

Lima, C. (2015). Música em cena: à escuta do documentário brasileiro. Minas Gerais: Tese de Doutorado, Faculdade de Filosofia e Ciências Humanas da Universidade Federal de Minas Gerais.

Ramos, L. (2012). Como explicar o ímpeto do documentário musical brasileiro?. DOC Online, (12), 127-150. 